\title{
The viscosity at the glass transition of a liquid lubricant
}

\section{Scott BAIR}

Center for High-Pressure Rheology, George W. Woodruff School of Mechanical Engineering, Georgia Institute of Technology, Atlanta GA 30332-0405, USA

Received: 07 November 2017 / Revised: 29 December 2017 / Accepted: 29 January 2018

(C) The author(s) 2018. This article is published with open access at Springerlink.com

\begin{abstract}
In the classical study of elastohydrodynamic lubrication (EHL) which does not employ real, measurable viscosity in analysis, the possibility of a glass transition has not been considered in many years. Indeed, the two rheological assumptions of classical EHL, the Newtonian inlet and the equivalence of a traction curve to a flow curve, would not have persisted so long had the pressure dependence of the viscosity been accurately stated. With the recent appearance of viscosity obtained from viscometers in EHL analysis, the possibility of a glass transition in the contact should be reexamined, especially for the fragile traction fluids. This article employs published data for a synthetic cycloaliphatic hydrocarbon to estimate the glass transition viscosity so that, when using real viscosities in EHL simulations, the state of the liquid may be assessed. Far into the glassy state the liquid should be treated as an elastic solid with a yield stress.
\end{abstract}

Keywords: elastohydrodynamic lubrication; glass transition; high pressure viscosity; EHL friction

\section{Introduction}

The glass transition in elastohydrodynamic lubrication (EHL) liquids under pressure has been the subject of discussion and speculation for more than forty years $[1,2]$. The glass transition has not been a recent topic of classical EHL as the viscosity there is described by simple pressure relations based on fictional accounts [3] of viscometer measurements in which the viscosity does not usually reach to the large values for which the transition occurs. With the recent move towards quantitative EHL [4], which employs real thermophysical properties, the glass transition in EHL liquids should be reexamined.

The limiting low shear viscosity at the glass transition is most often given by a "rule-of-thumb" as $\mu_{\mathrm{g}}=1 \times 10^{12} \mathrm{~Pa} \cdot \mathrm{s}$ [5] which seems to be more appropriate for molten minerals [6] than organic liquids. Experimental measurements of the glass transition and the viscosity of liquid lubricants over a range of temperature and pressure more than thirty years ago
[7] indicated that the glass viscosity must be much smaller, $10^{7} \mathrm{~Pa} \cdot \mathrm{s}$ to $10^{9} \mathrm{~Pa} \cdot \mathrm{s}$. Schweyer [8] found $\mu_{\mathrm{g}}=$ $10^{8} \mathrm{~Pa} \cdot \mathrm{s}$ for asphalts under pressure. Measurements at ambient pressure of viscosity up to $3.7 \times 10^{8} \mathrm{~Pa} \cdot \mathrm{s}$ from the University of Chicago [9] compared with glass transition measurements by transient hot-wire at Umea University [10] give the viscosity at the transition to be $\mu_{\mathrm{g}}=1.23 \times 10^{7} \mathrm{~Pa} \cdot \mathrm{s}$ for squalane when the observation time is 0.3 seconds.

\section{Glass transition temperature and pressure}

Glass transition temperatures and pressures [11] and precise viscosity [12] data exist for a liquid lubricant, MCS 460, a cycloaliphatic synthetic hydrocarbon produced by Monsanto. It is one of the model lubricants for which the properties have been tabulated by Hamrock et al. [13], although the pressure-viscosity plots in Ref. [13] are extrapolations not representative of the measured viscosity for this oil. MCS 460 displays a dynamic crossover in both the temperature-viscosity

* Corresponding author: Scott BAIR, E-mail: scott.bair@me.gatech.edu 


\begin{tabular}{|c|c|c|c|}
\hline \multicolumn{4}{|c|}{ Nomenclature } \\
\hline$C_{\mathrm{F}}$ & fragility parameter in the Johari and Whalley equation & $T_{\mathrm{g}}$ & glass transition temperature, $\mathrm{K}$ \\
\hline$D_{\mathrm{F}}$ & fragility parameter in the VTF equation & $T_{\infty}^{\infty}$ & divergence temperature, $\mathrm{K}$ \\
\hline$p$ & pressure, $\mathrm{Pa}$ & $\mu$ & limiting low-shear viscosity, Pa.s \\
\hline$p_{\infty}$ & pressure at which viscosity diverges, $\mathrm{Pa}$ & $\mu_{0}$ & low-shear viscosity at $p=0, \mathrm{~Pa} \cdot \mathrm{s}$ \\
\hline$p_{\mathrm{g}}$ & glass transition pressure, $\mathrm{Pa}$ & $\mu_{\mathrm{g}}$ & low-shear viscosity at the glass transition, Pa-s \\
\hline$T$ & temperature, $\mathrm{K}$ & $\mu_{\mathrm{JW}}$ & parameter in the Johari \&Whalley relation, Pa.s \\
\hline & crossover temperature, $\mathrm{K}$ & $\mu_{\infty}$ & low-shear viscosity at infinite $T, \mathrm{~Pa} \cdot \mathrm{s}$ \\
\hline
\end{tabular}

and the pressure-viscosity response at a viscosity of the order of $100 \mathrm{~Pa} \cdot \mathrm{s}$ [12]. A dynamic crossover is not unusual in fragile liquids.

The relative volumes in isobaric cooling and isothermal compression experiments are plotted in Figs. 1 and 2, respectively. These measurements were performed in dilatometers described in [14]. For characterization of the temperature and pressure of the glass transition, it is not necessary to precisely determine volumes (or densities), only the relative changes in volume. The relative volumes reported in Figs. 1 and 2 represent the positions of a piston that applies the pressure and is not corrected for the elastic deformation of the containment and is, therefore, only a representation of the liquid volume through an unknown linear relationship.

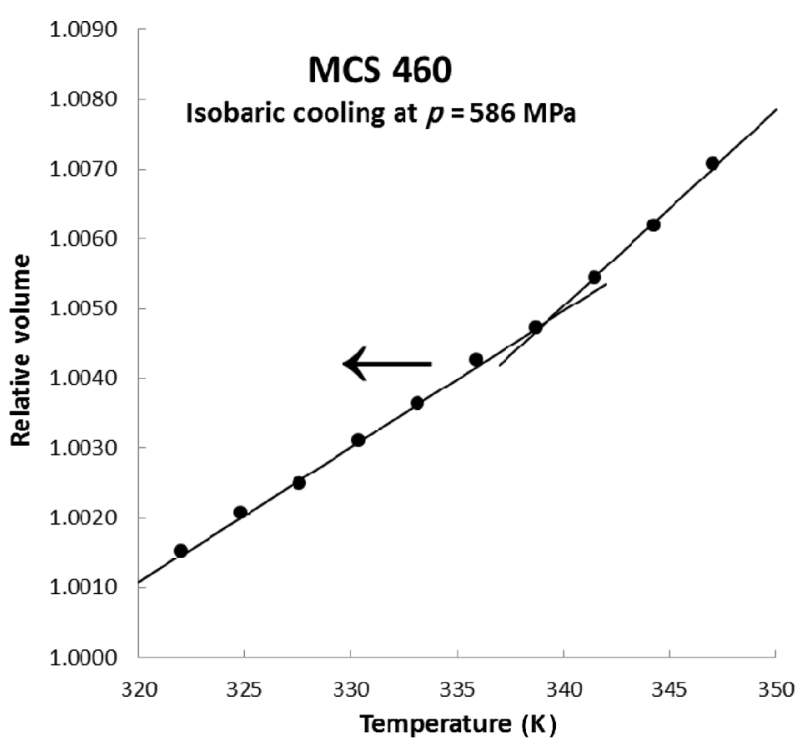

Fig. 1 The glass transition detected in isobaric cooling at pressure of $586 \mathrm{MPa}$. The arrow indicates the time sequence in which the measurements were made.
All measured glass temperatures for pressures from 400 to $700 \mathrm{MPa}$ are shown in Fig. 3 and listed in Table 1.

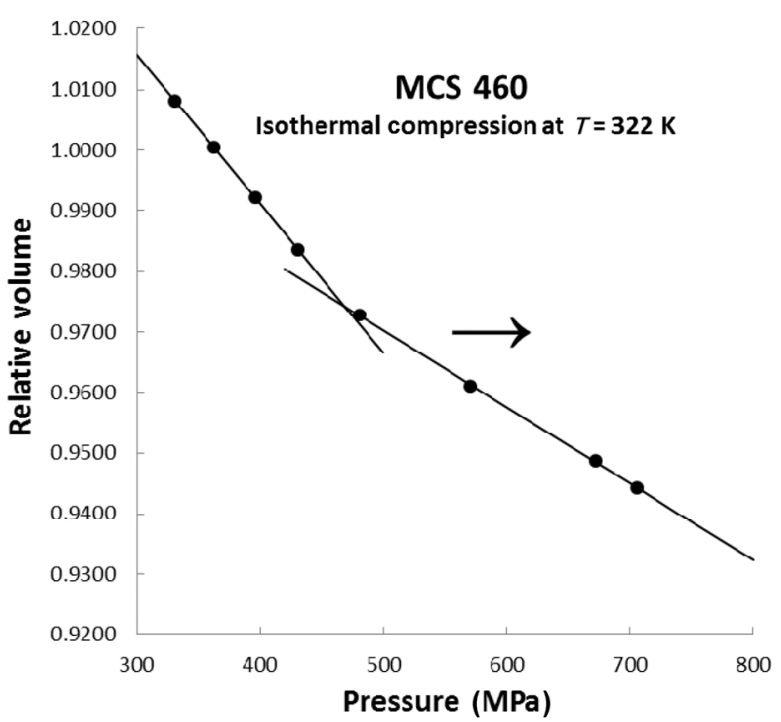

Fig. 2 The glass transition detected in isothermal compression at $322 \mathrm{~K}$. The arrow indicates the time sequence in which the measurements were made.

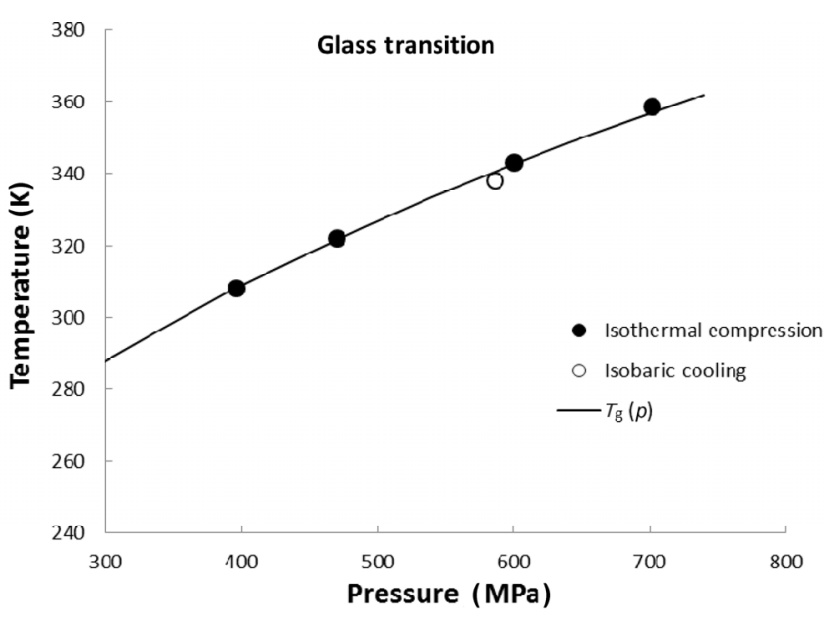

Fig. 3 The glass transition temperature as a function of pressure and the correlation of Oelsand Rehage. 
Table 1 The glass transition state (pressure and temperature) from experiment.

\begin{tabular}{ccc}
\hline Path & $p / \mathrm{MPa}$ & $T / \mathrm{K}$ \\
\hline Isobaric cooling & 586 & 338 \\
Isothermal compression & 397 & 308 \\
Isothermal compression & 470 & 322 \\
Isothermal compression & 601 & 343 \\
Isothermal compression & 701 & 358 \\
\hline
\end{tabular}

The curve fitted to these data represents the equation of Oels et al. [15]:

$$
T_{\mathrm{g}}(p)=T_{\mathrm{g} 0}+A_{1} \ln \left(1+A_{2} p\right)
$$

with $T_{\mathrm{g} 0}=196.1 \mathrm{~K}\left(-81.55^{\circ} \mathrm{C}\right), A_{1}=130.16 \mathrm{~K}$, and $A_{2}=3.652 \mathrm{GPa}^{-1}$. The fit is good with average absolute deviation of $0.9 \mathrm{~K}$.

\section{Temperature and pressure dependence of viscosity}

Extrapolations of viscosity to the glass transition may be bedeviled by a dynamic crossover as shown in Fig. 4 for the temperature dependence of the viscosity [12] of MCS 460 at $300 \mathrm{MPa}$. A crossover occurs at slightly higher temperature or slightly lower pressure than the glass transition and represents a change from one

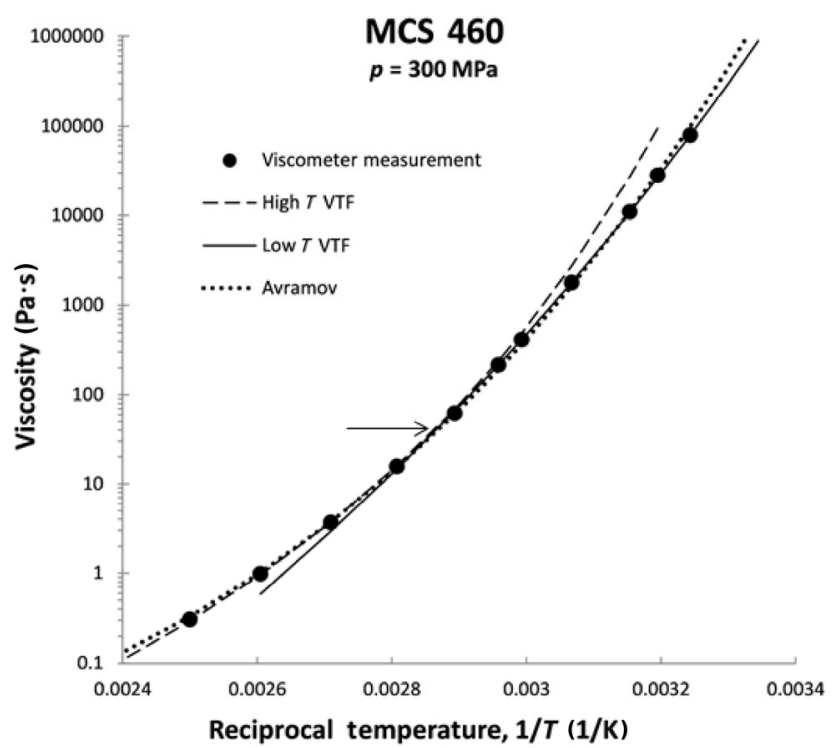

Fig. 4 The temperature dependence showing a crossover (at the horizontal arrow) which can be best represented by two VTF equations or with less accuracy by a single Avramov equation. temperature-viscosity relation (or pressure-viscosity relation) to another. The crossover occurs at approximately the same viscosity regardless of the pressure or temperature. When a crossover occurs, the Eq. (2) as described by Vogel, Tammann and Fulcher (VTF) [16] must be applied over two adjacent temperature intervals for an accurate fit to the data in Fig. 4.

$$
\mu=\mu_{\infty} \exp \left[\frac{D_{\mathrm{F}} T_{\infty}}{T-T_{\infty}}\right]
$$

For temperatures above the crossover, greater than $345 \mathrm{~K}, \mu_{\infty}=8.20 \times 10^{-6} \mathrm{~Pa} \cdot \mathrm{s}, D_{\mathrm{F}}=6.92$ and $T_{\infty}=241 \mathrm{~K}$ with average absolute deviation of the relative viscosity (AARD) of $2.0 \%$. For temperatures below the crossover, less than $345 \mathrm{~K}, \mu_{\infty}=2.40 \times 10^{-10} \mathrm{~Pa} \cdot \mathrm{s}, D_{\mathrm{F}}=27.2$ and $T_{\infty}=170 \mathrm{~K}$ with $\mathrm{AARD}=2.5 \%$. The crossover viscosity is about $47 \mathrm{~Pa} \cdot \mathrm{s}$ [12].

Another correlation is plotted in Fig. 4, the Avramov \& Milchev equation [17]

$$
\mu=\mu_{\infty} \exp \left[\frac{A}{T}\right]^{q}
$$

which sometimes provides the temperature-viscosity response across an ostensible crossover with a single expression [18] and accuracy similar to the two VTF equations. The fitted Avramov equation in Fig. 4 represents $\mu_{\infty}=1.639 \times 10^{-3} \mathrm{~Pa} \cdot \mathrm{s}, \quad q=4.675$ and $A=571.6 \mathrm{~K}$ with $\mathrm{AARD}=7.3 \%$ and is less accurate than the double VTF form.

Crossovers were seen for the pressure dependence of MCS 460 as well as shown for example in Fig. 5 for $T=313 \mathrm{~K}$ where the crossover occurs for $\mu=56 \mathrm{~Pa} \cdot \mathrm{s}$ [12]. The curves in the figure are the pressure analog of the VTF equation, the Johari and Whalley (J\&W) equation [19]

$$
\mu=\mu_{\mathrm{JW}} \exp \left[\frac{C_{\mathrm{F}} p_{\infty}}{p_{\infty}-p}\right]
$$

for pressures less than $200 \mathrm{MPa}, \mu_{\mathrm{JW}}=1.194 \times 10^{-14}$ $\mathrm{Pa} \cdot \mathrm{s}, C_{\mathrm{F}}=28.4$ and $p_{\infty}=0.88 \mathrm{GPa}$ with $\mathrm{AARD}=0.9 \%$. For pressures greater than $200 \mathrm{MPa}$, to fit the data with $\mathrm{AARD}=0.7 \%, C_{\mathrm{F}}$ and $p_{\infty}$ must both be very large with $C_{\mathrm{F}} / p_{\infty}=55.11 \mathrm{GPa}^{-1}$. This is Arrhenius response with $\mu_{\mathrm{JW}} \exp \left(C_{\mathrm{F}}\right)=1.859 \times 10^{-3} \mathrm{~Pa} \cdot \mathrm{s}$. 


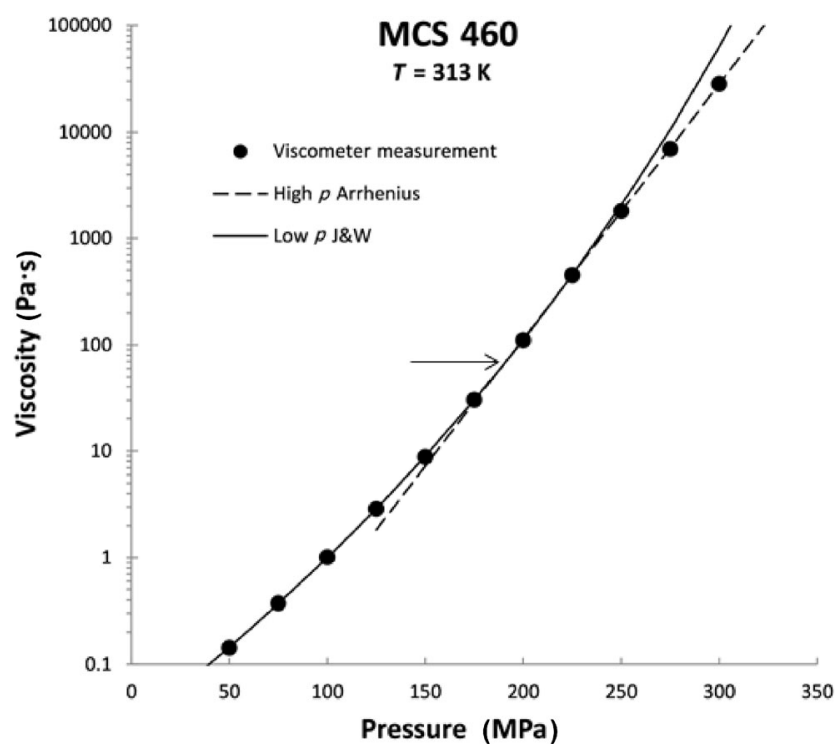

Fig. 5 The pressure dependence at $313 \mathrm{~K}$ showing a crossover (at the horizontal arrow) which can be best represented by two J\&W equations (4).

$$
\mu=\mu_{\mathrm{JW}} \exp \left(C_{\mathrm{F}}\right) \exp \left(\frac{C_{\mathrm{F}}}{p_{\infty}} p\right)
$$

The equation above is plotted in Fig. 5 marked as Arrhenius. The parameters of the $\mathrm{J} \& \mathrm{~W}$ equation are tabulated in Ref. [12] for the other measured isotherms.

Of course, thermal EHL analysis requires a temperature as well as pressure correlation such as the free volume models. The free volume approach cannot reproduce the crossover [12]. Thermodynamic scaling [20] is promising; however, it also requires the equation of state.

The underlying mechanism of the crossover remains the subject of intense speculation and research. An excellent and detailed discourse on possible mechanisms has been contributed by Roland and coworkers [21].

\section{Viscosity at the glass transition}

The viscosities at the glass transition condition may now be calculated at the pressure $(300 \mathrm{MPa})$ for which a viscosity isobar was obtained and the five temperatures ( $293 \mathrm{~K}$ to $388 \mathrm{~K}$ ) for which viscosity isotherms were measured in Ref. [12]. See Table 2. The transition viscosity varies from $2.30 \times 10^{7} \mathrm{~Pa} \cdot \mathrm{s}$ to $15.6 \times$
$10^{7} \mathrm{~Pa} \cdot \mathrm{s}$ with the arithmetic average being $6.2 \times 10^{7} \mathrm{~Pa} \cdot \mathrm{s}$ and the geometric mean being $4.7 \times 10^{7} \mathrm{~Pa} \cdot \mathrm{s}$. This is in the same range as for the EHL reference liquid squalane [10]. The glass transition viscosity is much less than the "universal value" of $10^{12} \mathrm{~Pa} \cdot \mathrm{s}$. Using the "universal" glass transition viscosity and the extrapolations of Barus and Roelands pressureviscosity equations given by Hamrock [13] for this oil at $311 \mathrm{~K}$, the glass transition pressure would be $955 \mathrm{MPa}$ and $855 \mathrm{MPa}$ for Barus and Roelands, respectively. In fact, the glass transition pressure should be about $410 \mathrm{MPa}$ as shown in Fig. 6 and this oil will be in the glassy condition for a portion of an EHL contact at this temperature.

Table 2 The glass transition state (pressure and temperature) from the Oels and Rehage equation (1) and the viscosity calculated by the given correlation.

\begin{tabular}{cccc}
\hline$p / \mathrm{MPa}$ & $T_{\mathrm{g}} / \mathrm{K}$ & $\mu_{\mathrm{g}} / \mathrm{Pa} \cdot \mathrm{s}$ & Viscosity correlation \\
\hline 300 & 288 & $8.69 \times 10^{7}$ & Avramov\&Milchev \\
300 & 288 & $2.70 \times 10^{7}$ & Low TVTF* \\
323 & 293 & $3.08 \times 10^{7}$ & High $p$ J\&W (Arrhenius) \\
422 & 313 & $2.35 \times 10^{7}$ & High $p$ J $\mathrm{W}$ (Arrhenius) \\
569 & 338 & $2.30 \times 10^{7}$ & High $p \mathrm{~J} \& \mathrm{~W}$ (Arrhenius) \\
829 & 373 & $8.64 \times 10^{7}$ & High $p \mathrm{~J} \& \mathrm{~W}$ (Arrhenius) \\
964 & 388 & $1.56 \times 10^{8}$ & High $p \mathrm{~J} \& \mathrm{~W}$ (Arrhenius) \\
\hline
\end{tabular}

*The high temperature VTF relation gives $\mu_{\mathrm{g}}=2.3 \times 10^{10} \mathrm{~Pa} \cdot \mathrm{s}$ for this state.

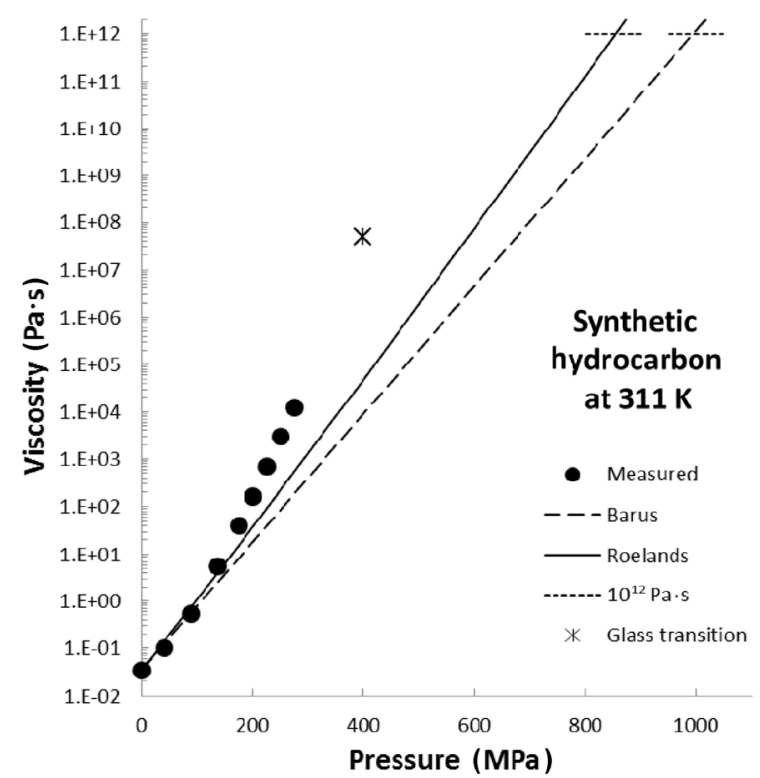

Fig. 6 The Barus and Roelands extrapolations of Hamrock et al. [13] compared with the measurements and showing the glass transition pressure. 


\section{Conclusion}

For much of the last forty years, the temperature and pressure dependence of viscosity in EHL has been specified by simple models which prevent the viscosity from reaching realistic values. With the recent trend toward the use of real viscosity in analyses, the possibility of a glass transition in the lubricant film cannot be overlooked. This event is more likely for the liquids designed for high friction, traction fluids, which are also susceptible to a dynamic crossover. The glass transition is a phenomenon occurring at a specific value of viscosity for a given liquid. It seems well-established that for the much studied inorganic liquids (mineral melts) the glass transition viscosity is of the order of $10^{12} \mathrm{~Pa} \cdot \mathrm{s}$, as in Ref. [22] for example. However, the situation for organic liquids is less clear $[7,8]$. Here, for one liquid lubricant, the glass transition by dilatometry combined with falling cylinder viscometry places the viscosity at the transition at between $10^{7} \mathrm{~Pa} \cdot \mathrm{s}$ and $10^{8} \mathrm{~Pa} \cdot \mathrm{s}$, in the same range as squalane [10].

Open Access: The articles published in this journal are distributed under the terms of the Creative Commons Attribution 4.0 International License (http:// creativecommons.org/licenses/by/4.0/), which permits unrestricted use, distribution, and reproduction in any medium, provided you give appropriate credit to the original author(s) and the source, provide a link to the Creative Commons license, and indicate if changes were made.

\section{References}

[1] Johnson K L, Cameron R. Fourth paper: shear behaviour of elastohydrodynamic oil films at high rolling contact pressures. Proc Inst Mech Eng 182(1): 307-330 (1967)

[2] Alsaad M A, Winer W O, Medina F D, O'Shea D C. Lightscattering study of the glass transition in lubricants. $J \mathrm{Lubr}$ Technol 100(3): 418-422 (1978)

[3] Bair S. Comment on "The relationship between friction and film thickness in EHD point contacts in the presence of longitudinal roughness" by Guegan, Kadiric, Gabelli, \& Spikes. Tribol Lett 65(3): 83 (2017)

[4] Bair S, Fernandez J, Khonsari M M, Krupka I, Qureshi F, Vergne P, Wang Q J. Letter to the editor: An argument for a change in elastohydrodynamic lubrication philosophy. Proc Inst Mech Eng Part J 223(4): 1-12 (2009)

[5] Casalini R, Roland C M. Why liquids are fragile. Phys Rev E Stat Nonlin Soft Matter Phys 72(3): 031503 (2005)

[6] Giordano D, Potuzak M, Romano C, Dingwell D B, Nowak M. Viscosity and glass transition temperature of hydrous melts in the system $\mathrm{CaAl}_{2} \mathrm{Si}_{2} \mathrm{O}_{8}-\mathrm{CaMgSi}_{2} \mathrm{O}_{6}$. Chem Geol 256(3-4): 203-215 (2008)

[7] Yasutomi S, Bair S, Winer W O. An application of a free volume model to lubricant rheology I-Dependence of viscosity on temperature and pressure. J Tribol 106(2): 291-302 (1984)

[8] Schweyer H E. Glass transition of asphalts under pressure. $J$ Test Eval 2(1): 50-56 (1974)

[9] Deegan R D, Leheny R L, Menon N, Nagel S R, Venerus D C. Dynamic shear modulus of tricresyl phosphate and squalane. J Phys Chem B 103(20): 4066-4070 (1999)

[10] Bair S S, Andersson O, Qureshi F S, Schirru M M. New EHL modeling data for the reference liquids Squalane and Squalane plus polyisoprene. Tribol Trans (2017) doi: 10.1080/10402004.2017.1310339

[11] Alsaad M, Bair S, Sanborn D M, Winer W O. Glass transitions in lubricants: its relation to Elastohydrodynamic lubrication (EHD). J Lubr Technol 100(3): 404-416 (1978)

[12] Bair S, Roland C M, Casalini R. Fragility and the dynamic crossover in lubricants. Proc Inst Mech Eng Part J J Eng Tribol 221(7): 801-811 (2007)

[13] Hamrock B J, Schmid S R, Jacobson B O. Fundamentals of Fluid Film Lubrication. 2nd ed. New York (USA): Marcel Dekker, 2004: 91-95.

[14] Bair S S. High Pressure Rheology for Quantitative Elastohydrodynamics. Amsterdam (Germany): Elsevier Science, 2007: 56-57.

[15] Oels H J, Rehage G. Pressure-volume-temperature measurements on Atactic polystyrene. A thermodynamic view. Macromolecules 10(5): 1036-1043 (1977)

[16] Angell C A. Relaxation in liquids, polymers and plastic crystals - strong/fragile patterns and problems. J Non-Cryst Solids 131-133: 13-31 (1991)

[17] Avramov I, Milchev A. Effect of disorder on diffusion and viscosity in condensed systems. J Non-Cryst Solids 104(2-3): 253-260 (1988)

[18] Harris K R, Kanakubo M. High pressure studies of the transport properties of ionic liquids. Faraday Discuss 154: 425-438 (2012)

[19] Johari G P, Whalley E. Dielectric properties of glycerol in the range $0.1-10^{5} \mathrm{~Hz}, 218-357 \mathrm{~K}, 0-53 \mathrm{~kb}$. Faraday Sym Chem Soc 6: 23-41 (1972) 
[20] Casalini R, Paluch M, Roland C M. The dynamic crossover region in phenol-and cresol-phthalein-dimethylethers under different conditions of pressure and temperature. $J$ Phys Condens Matter 15(11): S859-S867 (2003)

[21] Roland C M, Hensel-Bielowka S, Paluch M, Casalini R. Supercooled dynamics of glass-forming liquids and polymers

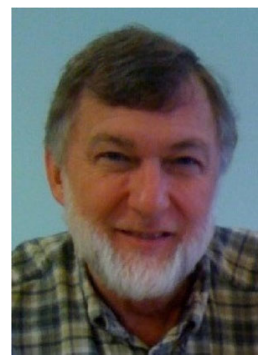

Scott BAIR. He received the B.S., M.S. and Ph.D degrees in mechanical engineering from Georgia Institute of Technology where he is Regents' Researcher in the George W. Woodruff under hydrostatic pressure. Rep Prog Phys 68(6): 1405-1478 (2005)

[22] Matusita K, Koide M, Komatsu T. Viscosity of fluoride glasses at glass transition temperature. J Non-Cryst Solids 140: 119-122 (1992)

School of Mechanical Engineering. He has been performing experimental research in high pressure rheology for 44 years and has eleven U.S. patents and has published more than 180 journal articles. 